\title{
Higher levels of tumor necrosis factor $\beta$ are associated with frailty in socially vulnerable community-dwelling older adults
}

\author{
Carla M. C. Nascimento, Marisa S. Zazzetta, Grace A. O. Gomes, Fabiana S. Orlandi, Karina Gramani-Say, \\ Fernando A. Vasilceac, Aline C. M. Gratão, Sofia C. I. Pavarini and Marcia R. Cominetti ${ }^{*}$ (i)
}

\begin{abstract}
Background: The complex physiology underpinning the frailty syndrome is responsible for the absence of robust biomarkers that can be used for screening, diagnostic and/or prognostic purposes and has made clinical implementation difficult. Considering socially vulnerable populations, who have poor health status and increased morbidity and mortality, this scenario is even more complex. However, to the best of our knowledge, there are no studies available to investigate frailty biomarkers in socially vulnerable populations. Thus, the aim of this cross-sectional study was to identify potential blood-based biomarkers of frailty in a socially vulnerable population.

Methods: A sample consisting of 347 community-dwelling older people living in a context of high social vulnerability was divided into non-frail (robust), pre-frail and frail groups, according to modified Fried frailty phenotype criteria. Blood samples were collected and analyzed for basic metabolic parameters and for inflammatory cytokines.

Results: Levels of Interleukin-1a (IL-1a) and Tumor Necrosis Factor a (TNF-a) were significantly higher in pre-frail subjects, compared to non-frail ones. Tumor Necrosis Factor $\beta$ (TNF- $\beta$ ) levels presented higher values in the frail compared to non-frail individuals. Interleukin-6 (IL-6) levels in pre-frail and frail subjects were significantly higher compared to the levels of non-frail subjects. Using an ordinal regression analysis, we observed that socially vulnerable older people at higher risk of developing frailty were subjects above 80 years old (OR: 2.5; 95\% Cl: 1.1-5.6) and who presented higher levels of TNF- $\beta$ ( $\geq 0.81 \mathrm{pg} / \mathrm{mL}, \mathrm{OR}: 2.53 ; 95 \% \mathrm{Cl}: 1.3-4.9$ ).

Conclusion: As vulnerable populations continue to age, it is imperative to have a greater understanding of the frailty condition, identifying novel potential blood-based biomarkers. The results presented here could help to implement preventive healthcare strategies by evaluating frailty and at the same time measuring a set of inflammatory biomarkers, paying special attention to TNF- $\beta$ plasmatic levels.
\end{abstract}

Keywords: Aging, Biomarkers, Older people, Frailty, Tumor necrosis factor $\beta$

\section{Background}

Frailty is an age-related state characterized as a syndrome in which individuals may become more vulnerable to adverse health outcomes with a higher risk for mortality when exposed to stressors [1-3]. Social vulnerability is defined as the degree to which a person's overall social situation leaves them susceptible to health problems, which include physical, mental, psychological and functional problems. Social vulnerability is particularly

\footnotetext{
* Correspondence: mcominetti@ufscar.br

Department of Gerontology, Federal University of São Carlos, Rod.

Washington Luis, Km 235, Monjolinho, São Carlos, SP CEP 13565-905, Brazil
}

important for older adults as a condition related to cultural, social and economic aspects that may influence the access to goods and services. This is an important indicator to explain the high exposure of this population to the development of pathological and degenerative conditions as it increases the frailty rate [4-8].

On the other hand, knowledge regarding the cellular and molecular mechanisms related to this syndrome is limited, especially in vulnerable populations. Changes related to the immune-endocrine axis are extensively described during aging and are frequently associated to increases in morbidity and mortality [9]. These changes

(c) The Author(s). 2018 Open Access This article is distributed under the terms of the Creative Commons Attribution 4.0 International License (http://creativecommons.org/licenses/by/4.0/), which permits unrestricted use, distribution, and reproduction in any medium, provided you give appropriate credit to the original author(s) and the source, provide a link to the Creative Commons license, and indicate if changes were made. The Creative Commons Public Domain Dedication waiver (http://creativecommons.org/publicdomain/zero/1.0/) applies to the data made available in this article, unless otherwise stated. 
are characterized by a low-grade, controlled, asymptomatic, systemic, and chronic progressive increase in the pro-inflammatory status, also called inflammaging [10]. This pro-inflammatory state generated by age, sex, lifestyle, socioeconomic background, comorbidities and affective, cognitive or sensory impairments has been postulated as a potential driver of frailty pathogenesis, producing even higher levels of systemic inflammatory markers [11, 12]. Associations between frailty and endocrine and immune changes have been demonstrated, suggesting that alterations in these systems may accelerate the development of age-related diseases and consequently, frailty. [13, 14]. Considering that frailty is characterized by the loss of resilience, poor social conditions may reflect chronic stressors, which increase risk of disturbances in metabolic and immunological parameters, leading to a higher risk of developing frailty [15-17].

Previous studies have pointed out several candidates for blood-based biomarkers for frailty [18]. Those include inflammatory molecules, such as C-reactive protein (CRP) $[19,20]$, Interleukin-6 (IL-6) [19-22] and Tumor Necrosis Factor- $\alpha($ TNF- $\alpha)[19,21,23]$, clinical parameters such as hemoglobin [19, 24] and serum albumin [25], hormones, such as dehydroepiandrosterone sulfate (DHEA-S) [26], testosterone [27], Insulin-like Growth Factor-1 (IGF-1) [28] and vitamin D [29], among others. To the best of our knowledge, however, no study has described the differences of clinical parameters and pro-inflammatory cytokines so far among different frailty statuses of older adults living in socially vulnerable populations.

As a result, we performed a cross-sectional study to investigate potential blood-based biomarkers for frailty under a social vulnerability context, considering demographic, psychological and clinical characteristics. The results of this study could contribute to a greater understanding of frailty syndrome in socially vulnerable populations, as well as to the biology of frailty with regards to the panel of expressed inflammatory cytokines. Moreover, identifying potential blood-based biomarkers will enable the development of interventions and specific policies for this public.

\section{Methods}

\section{Sample}

A total of 852 older adults fulfilled the eligibly criteria and were registered in the database. Based on this, the adequate sample size was calculated according to the multinomial statistics analysis. Thus, 347 representative participants were stratified according to sex and age sample. This sample size provided a power of $95 \%$, considering a medium effect size $(50 \% ; p=0.50)$. Participants who accepted to take part in the study and signed the consent term were asked to collect blood samples. Immediately after drawing blood, the clinical assessment for frailty status was scheduled.

\section{Study protocol}

The study protocol (860.653/2014) and informed consent form received ethics approval from the Federal University of São Carlos Ethics Committee on Human Experimentation. Written informed consent concerning the conduct of the survey was obtained from each participant, and complete anonymity of participants was assured as described earlier [30].

Brazil has a Unified Health System (Sistema Unico de Saúde - SUS), and it is estimated that more than $75 \%$ of the Brazilian population rely exclusively on it for their health care. The Family Health Program is a part of the unified health system created to provide mainly primary care health [31]. Since we consider that these units are located mainly in vulnerable areas, most people living in these zones are users and are registered on the SUS database. All people that use the health care service must be registered and accompanied by a team of health professionals. For this study, older adults (60 years and over) were selected, who were registered in the SUS database in a region with a high rate of social vulnerability and poverty in São Carlos, São Paulo, Brazil, called "Cidade Aracy", which is a region with a high rate of poverty that unifies five public clinical practice units. Social vulnerability was determined using the Paulista Social Vulnerability Index (PSVI) that measures social exclusion in different cities in São Paulo state, Brazil [32]. SVI allows the classification of a determined population into seven groups: 1 - extremely low; 2 - very low; 3 - low; 4 - medium; 5 - high; 6 - very high vulnerability and 7 rural areas of high vulnerability (Additional file 1). Based on these criteria, the study population was classified as level 5 of vulnerability, which represents populations living in urban areas with high vulnerability. This instrument was used with the unique intention to determine the social vulnerability of the studied population, not for comparison purposes.

Subjects were classified according to diagnostic criteria based on the classification proposed by Fried and co-workers [1] and validated in Brazil by Nunes and colleagues [33], as described in the study protocol. According to these criteria, the subjects were classified into three groups: frail (scores 3-5), pre-frail (scores 1, 2), and non-frail (score 0). For the diagnosis of frailty, five items were considered: 1) non intentional weight loss was evaluated by means of self-report considering losses of more than $4.5 \mathrm{~kg}$ during the last year; 2) fatigue was assessed considering the answers given to two items from the Center of Epidemiological Study Center Scale (CES-D): "Have you felt that you had to make an effort to do your customary tasks?" and "Were you unable to proceed when doing your things?" [34]; 3) Handgrip strength was measured using a manual dynamometer and was considered the measure of the highest force 
possible produced for the dominant upper limb in three attempts. These values were adjusted considering gender and body mass index (BMI) for the final criteria; 4) physical inactivity was evaluated by applying the International Physical Activity Questionnaire (IPAQ) [35], which assesses the amount of physical activity performed by the individual and the estimated caloric expenditure. Individuals with a caloric expenditure in the first quintile were considered positive for this item; 5) low-gait speed was measured using a $4.6-\mathrm{m}$-long circuit and the time spent to go through the circuit. The individuals in the first quintile, after adjusting their respective heights and genders, were considered positive for this item.

Sociodemographic and clinical data were also assessed: age, sex, education, ethnicity, cognitive function measured by the Mini Mental State Examination [36], depressive symptoms measured by the Geriatric Depression Scale, GDS-15, Brazilian version [37], leisure-time of physical activity measured by the self-report specific part of the International Physical Activity Questionnaire [35], medications, Body Mass Index (BMI), marital status and per capita income. In an effort to avoid potential sources of bias, all the interviews were conducted by trained gerontologists and data was included using the software Epidata ${ }^{\circ}$ software.

\section{Analysis of biomarkers}

Fasting blood samples were collected on a visit closest to the frailty assessment. Samples were collected using EDTA tubes, mixed by inversion and centrifuged (3000 rpm, $5 \mathrm{~min}$ ) to separate plasma. Plasma samples were stored at $-80{ }^{\circ} \mathrm{C}$ until they were analyzed. One plasma aliquot was used to perform measures of glucose, insulin, total cholesterol, triglycerides, urea, creatinine, dehydroepiandrosterone (DHEA), dehydroepiandrosterone sulfate (S-DHEA), human growth hormone $(\mathrm{GH})$, insulin-like growth factor 1 (IGF-1) and glycated hemoglobin in a specialized clinical laboratory.

Another aliquot was used to measure the level of inflammatory cytokines. For that, $25 \mu \mathrm{L}$ of samples were added to each well of a 96-well plate provided with the kit (HCYTOMAG, MILLIPLEX ${ }^{\circ}$ MAP Kit EMD Millipore Corp., MA, USA). Plates were incubated under agitation on a shaker for $2 \mathrm{~h}$ at room temperature $\left(20-25^{\circ} \mathrm{C}\right)$. Next, after washing according to the instructions provided in the kit, $25 \mu \mathrm{L}$ of premixed beads containing the primary antibodies to detect the specific cytokines evaluated (Interleukin-1 $\alpha$; Interleukin-1 $\beta$; Interleukin-6; Tumor Necrosis Factor $\alpha$ and Tumor Necrosis Factor $\beta$ ) were inserted in each well. The plate was sealed and incubated for $2 \mathrm{~h}$ at room temperature $\left(20-25^{\circ} \mathrm{C}\right)$. Afterwards, the plates were washed twice with the washing solution provided and $25 \mu \mathrm{L}$ of streptavidin-phycoerythrin solution was added to each well and plates were incubated with agitation on a shaker for $30 \mathrm{~min}$ at room temperature. A standard curve was prepared with the reagents provided in the kit and luminescence readings were performed on a plate reader (Luminex xMAP ${ }^{\circ}$.

\section{Statistical analysis}

To describe the profile samples for all variables, data were presented in frequency tables for categorical data and descriptive statistics were applied for numerical data with means and standard deviation. In order to compare categorical data, the chi-square and the Fisher exact tests were used. When comparisons involved three levels of frailty (non-frail, pre-frail and frail individuals), the Kruskal-Wallis test was used due to the non-normal distribution of the data. To compare numerical variables according to frailty status adjusted for sex and age, an analysis of covariance (ANCOVA) was applied. Univariate analysis was performed to assess the association between factors and outcome measures. Variables considered with a significance of at least $20 \%(\mathrm{p}<=0.20)$ in the univariate analysis were all included in the multivariable ordinal logistic regression. In this model, variables were considered significant at $p \leq 0.05$. All statistical analyses were performed using the SAS System for Windows (Statistical Analysis System), version 9.2 (SAS Institute Inc., 2002-2008, Cary, NC, USA).

\section{Results}

The mean age of the study cohort was $70.1 \pm 7.7$ years, mostly female $(56.2 \%)$ with a low education level (3.8 \pm 2.3 years) (data not shown). In this sample, 34 subjects (9.8\%) were non-frail, 197 (56.8\%) were classified as pre-frail and 116 (33.4\%) subjects fulfilled the criteria for physical frailty. Considering age, as expected, frail individuals were significantly older than their non-frail counterparts (Table 1).

Results showed significant differences between groups concerning the sex, indicating that women were more frequent in the non-frail group, while men were most frequent in pre-frail and frail categories. Regarding age, as expected, older people ( $>80$ years) were frailer compared to those in the age groups of 60-69 and 7079 years. The Geriatric Depression Scale (GDS) indicated that prevalence of depressive symptoms was also higher in pre-frail and frail, compared to non-frail individuals. Frail individuals also presented insufficient levels of physical activity evaluated by the International Physical Activity Questionnaire (IPAQ) (Table 1), which is consistent to the frailty condition.

Considering the results of metabolic parameters and biomarker evaluation, we observed that urea and TNF- $\beta$ were significantly higher in frail participants compared to non-frail individuals. Levels of creatinine and IL-6 were higher among pre-frail and frail individuals, compared to 
Table 1 Sociodemographic characteristics and clinical parameters of participants distributed according to the Fried frailty scale, $n=347$

\begin{tabular}{|c|c|c|c|c|}
\hline & Non-frail & Pre-frail & Frail & $p$-value \\
\hline & $\begin{array}{l}n=34 \\
(9.8 \%)\end{array}$ & $\begin{array}{l}n=197 \\
(56.8 \%)\end{array}$ & $\begin{array}{l}n=116 \\
(33.4 \%)\end{array}$ & \\
\hline$\overline{\text { Age }(\%)}$ & & & & 0.003 \\
\hline $60-69$ years & 52.9 & $59.4^{*}$ & 43.1 & \\
\hline 70-79 years & $47.1^{*}$ & 28.4 & 37.1 & \\
\hline$>80$ years & 0.0 & 12.2 & $19.8^{*}$ & \\
\hline Sex (Men/women, \%) & $20.6 / 79.4^{*}$ & $43.1^{*} / 56.9$ & $51.7^{*} / 48.3$ & 0.005 \\
\hline Schooling (\%) & & & & 0.161 \\
\hline 0 years & 0.0 & 1.5 & 4.3 & \\
\hline $1-4$ years & 76.9 & 72.8 & 82.6 & \\
\hline$>5$ years & 23.1 & 25.7 & 13.1 & \\
\hline Ethnicity (White/non-white, \%) & $44.1 / 55.9$ & $39.5 / 50.5$ & $43.9 / 56.1$ & 0.700 \\
\hline Global Cognitive State-MMSE (\%) & & & & 0.132 \\
\hline Without cognitive impairment & 58.8 & 60.7 & 49.1 & \\
\hline With cognitive impairment & 41.2 & 39.3 & 50.9 & \\
\hline Depressive Symptoms-GSD (\%) & 11.8 & $31.1^{*}$ & $40.5^{*}$ & 0.006 \\
\hline Physically Active Enough-IPAQ score (\%) & 73.5 & 61.9 & $29.3^{*}$ & $<0.001$ \\
\hline Medications (\%) & & & & 0.388 \\
\hline $0-5$ medications & 75.0 & 67.8 & 62.3 & \\
\hline$>6$ medications & 25.0 & 32.2 & 37.7 & \\
\hline Body Mass Index & $29.5 \pm 6.5$ & $28.6 \pm 5.9$ & $28.2 \pm 6.1$ & 0.906 \\
\hline Marital status (With/without partner, \%) & $64.7 / 35.3$ & $59.7 / 40.3$ & $52.6 / 47.4$ & 0.325 \\
\hline Per capita income & $280.4 \pm 151.3$ & $239.2 \pm 127.7$ & $220.3 \pm 126.5$ & 0.169 \\
\hline
\end{tabular}

Notes: Data are expressed as mean \pm SD or percentage of total sample; Body Mass Index was calculated as weight in kilograms divided by height in square meters. GDS: Geriatric Depression Scale; MMSE: Mini-Mental State Examination. Per capita incomes are in US dollars, according to the quotation made on October/ 2017. Chi-square test $\left(\chi^{2} w^{2}\right)$ was used for categorical variables and Kruskal-Wallis test for numerical variables. ${ }^{*}$ Values with statistical significance $(p<0.05)$ All other bold entries represent the $p$ values of significant results

non-frail ones. Cytokines IL- $1 \alpha$ and TNF- $\alpha$ levels were higher in pre-frail, compared to non-frail, but no statistically significant differences for these cytokines were found comparing non-frail with frail individuals (Table 2).

We performed a univariate regression analysis to track the main variables that seem to contribute to the frailty phenotype considering the three groups (frail vs pre-frail vs non-frail) evaluated. Variables were considered to be part of the ordinal model when they presented a statistical significance above $20 \%(p<0.20)$. Thus, we considered the following variables for our model: sex, age, HDL and VLDL cholesterols, urea, creatinine, triglycerides IL-1 $\beta$, IL-6 and TNF- $\beta$ (Table 3).

Given these results, an ordinal regression model was conducted in order to predict which variables were significantly associated with frailty. Results showed that age and TNF- $\beta$ levels were significantly associated with frail phenotype. Older people with increased risk to becoming frail were those older than 80 years (OR: 2.5 ; 95\% CI: $1.09-5.61)$ and who presented higher levels of TNF- $\beta$ (OR: 2.5; 95\% CI: 1.30-4.9) (Table 4).

\section{Discussion}

Frailty is a geriatric syndrome associated with disability and mortality outcomes in older people. In a recent multicenter, a population-based cross-sectional study showed a prevalence around $38 \%$ of frailty in Brazilian community-dwelling older people [38]. We identified in our sample, in which all individuals were living in a high social vulnerability context, that $33.4 \%$ of aged subjects investigated fulfilled criteria for physical frailty. A possible explanation for these differences may be related to the fact that in our study, most of the participants were in the 60 to 69 year old age group (53.3\%; data not shown) and few participants were above 80 years old (13.5\%; data not shown), while in a study carried out by Pereira et al. [38] the age group ranging from 60 to 69 years old represented only $36.4 \%$ of the sample. More importantly, in the study by Pereira et al. [38], the authors did not evaluate frailty using Fried's score, but instead used the frailty index (FI), which probably contributed to the difference found in both studies, regarding frailty prevalence. Accordingly, Collard et al. 
Table 2 Peripheral biomarkers of participants distributed according to the Fried frailty scale, $n=347$

\begin{tabular}{|c|c|c|c|c|}
\hline & $\begin{array}{l}\text { Non-frail } \\
n=34 \\
(11.2 \%)\end{array}$ & $\begin{array}{l}\text { Pre-frail } \\
n=197 \\
(58.2 \%)\end{array}$ & $\begin{array}{l}\text { Frail } \\
n=116 \\
(30.6 \%) \\
\end{array}$ & $p$-value \\
\hline Glucose (mg/dL) & $95.5 \pm 27.5$ & $98.7 \pm 44.5$ & $106.4 \pm 52.2$ & 0.640 \\
\hline Glycated hemoglobin (\%) & $5.8 \pm 1.7$ & $5.7 \pm 2.4$ & $5.7 \pm 2.8$ & 0.874 \\
\hline Insulin $(\mu \mathrm{mol} / \mathrm{L})$ & $8.4 \pm 5.5$ & $8.6 \pm 7.8$ & $8.7 \pm 8.1$ & 0.663 \\
\hline Total cholesterol (mg/dL) & $200.2 \pm 40.4$ & $195.2 \pm 43.1$ & $193.3 \pm 45.7$ & 0.435 \\
\hline HDL cholesterol (mg/dL) & $49.4 \pm 11.2$ & $48.3 \pm 13.5$ & $47.2 \pm 11.6$ & 0.497 \\
\hline LDL cholesterol (mg/dL) & $119.8 \pm 37.8$ & $119.6 \pm 34.2$ & $115.2 \pm 34.2$ & 0.441 \\
\hline VLDL cholesterol (mg/dL) & $32.3 \pm 23.0$ & $28.4 \pm 13.6$ & $30.2 \pm 16.3$ & 0.818 \\
\hline Triglycerides (mg/dL) & $146.2 \pm 61.2$ & $148.5 \pm 82.7$ & $151.4 \pm 89.7$ & 0.939 \\
\hline Urea (mg/dL) & $34.5 \pm 10.1$ & $35.5 \pm 11.6$ & $40.1 \pm 14.9$ & $0.013^{* a}$ \\
\hline Creatinine (mg/dL) & $0.8 \pm 0.2$ & $0.96 \pm 0.3$ & $1.1 \pm 0.5$ & $0.004^{* a, b}$ \\
\hline DHEA (ng/mL) & $4.1 \pm 4.5$ & $4.4 \pm 4.3$ & $4.3 \pm 4.5$ & 0.407 \\
\hline S-DHEA ( $\mu \mathrm{g} / \mathrm{dL})$ & $55.8 \pm 40.3$ & $67.2 \pm 48.4$ & $67.2 \pm 53.3$ & 0.423 \\
\hline IGF-1 (ng/mL) & $113.2 \pm 42.4$ & $119.7 \pm 47.5$ & $117.2 \pm 43.2$ & 0.776 \\
\hline Hydroxyvitamin D (ng/mL) & $22.1 \pm 5.6$ & $23.2 \pm 8.6$ & $22.2 \pm 7.8$ & 0.693 \\
\hline \multicolumn{5}{|l|}{ Inflammatory markers (pg/mL) } \\
\hline Interleukin-1a & $3.0 \pm 5.2$ & $6.8 \pm 12.5$ & $9.2 \pm 21.8$ & $0.027^{\mathrm{b}}$ \\
\hline Interleukin-1 $\beta$ & $1.9 \pm 2.8$ & $3.1 \pm 4.2$ & $3.4 \pm 4.4$ & 0.056 \\
\hline Interleukin-6 & $1.9 \pm 1.6$ & $2.1 \pm 4.2$ & $4.2 \pm 7.6$ & $0.012^{* a, b}$ \\
\hline Interleukin-10 & $1.3 \pm 2.0$ & $1.7 \pm 3.2$ & $3.6 \pm 12.4$ & 0.571 \\
\hline Tumor Necrosis Factor-a & $2.0 \pm 2.0$ & $3.6 \pm 5.8$ & $4.7 \pm 10.2$ & $0.035^{* b}$ \\
\hline Tumor Necrosis Factor- $\beta$ & $0.5 \pm 0.5$ & $3.0 \pm 11.5$ & $3.0 \pm 10.1$ & $0.033^{* a}$ \\
\hline
\end{tabular}

Notes: DHEA: Dehydroepiandrosterone; S-DHEA: Dehydroepiandrosterone sulfate; GH: Growth Hormone; IGF-1: Insulin-like growth factor 1. Kruskal-Wallis test. *Values with statistical significance $(p<0.05)$. ${ }^{a}$ Non-frail vs frail; ${ }^{b}$ non-frail vs pre-frail

All other bold entries represent the $p$ values of significant results

[39], in a systematic review of 21 studies $(n=61,500)$, described that the prevalence of frailty in a community-dwelling population has a high variability, ranging from 4 to $59.1 \%$. Moreover, in another study, Moreira and Lourenço [40] found a prevalence of $9.1 \%$ of frailty when a different scale was applied to track this phenotype, while Sousa et al. [41] found a prevalence of $17.1 \%$ for Brazilian older people using Fried's phenotype scale. These variations may be highlighted by the different operationalization of frailty status used in the studies, resulting in widely different frailty prevalences.

The frail condition in our sample was also more frequent in men, which is different from previously published epidemiological data that showed higher rates of frailty in women $[42,43]$. It has been demonstrated that men frequently have more acute illnesses, while women have more comorbidities and disabilities $[44,45]$. This may consequently lead to men becoming more vulnerable to frailty in advanced ages. Additionally, it is important to consider that Brazilian population social inequalities in health behavior are very relevant to explain the particularity of some results found for our sample. It has already been demonstrated that in low-income, less schooled people and those without private health insurance, Brazilian men were found to have more risk behavior, including smoking, sedentary lifestyles and bad quality of food, with a low intake of fruit and vegetables [46]. Furthermore, another investigation found that around $1.1 \%$ among men and $0.3 \%$ among women in this social condition have never visited a physician and 35\% and $52 \%$ of men and women respectively, had not visited a physician in the last year [47]. These findings help to elucidate the underutilization of health care services among individuals of the lowest economic class, but especially among men, which may characterize them as a more vulnerable group for frailty. On the other hand, our data is in accordance with other research, indicating that frailty increases with age and low levels of physical activity [39].

The aging process frequently results in a decline of the immune function, known as immunosenescense, which was related to the role of inflammation in frailty [48]. These alterations are characterized by around 2-fold increased levels of cytokine production when compared to young individuals' levels. Increases in adipose tissue, low levels of physical activity and the senescent cellular 
Table 3 Results of the univariate ordinal logistic regression analysis among groups (frail vs pre-frail vs non-frail)

\begin{tabular}{|c|c|c|c|c|}
\hline \multirow{2}{*}{ Variable } & \multirow[b]{2}{*}{ Category } & \multicolumn{2}{|c|}{ Univariate Regression } & \multirow[b]{2}{*}{$p$-value } \\
\hline & & O.R. & $95 \% \mathrm{Cl}$ & \\
\hline \multirow[t]{2}{*}{ Sex } & Women (ref.) & 1.00 & --- & --- \\
\hline & Men & 1.85 & $1.21-2.82$ & $0.004 *$ \\
\hline \multirow[t]{3}{*}{ Age (years) } & 60-69 years (ref.) & 1.00 & - & - \\
\hline & 70-79 years & 1.29 & $0.81-2.05$ & 0.278 \\
\hline & $\geq 80$ years & 2.65 & $1.41-5.00$ & $0.003^{*}$ \\
\hline \multirow{3}{*}{$\begin{array}{l}\text { Glucose (mg/dL) } \\
\text { (tertile) }\end{array}$} & $\leq 83$ (ref.) & 1.00 & - & - \\
\hline & $84-96$ & 0.99 & $0.59-1.67$ & 0.979 \\
\hline & $\geq 97$ & 1.06 & $0.64-1.77$ & 0.816 \\
\hline \multirow{3}{*}{$\begin{array}{l}\text { HDL cholesterol (mg/dL) } \\
\text { (tertile) }\end{array}$} & $\geq 51$ (ref.) & 1.00 & - & - \\
\hline & $42-50$ & 1.18 & $0.70-1.97$ & 0.538 \\
\hline & $\leq 41$ & 1.42 & $0.85-2.40$ & $0.184 *$ \\
\hline \multirow{3}{*}{$\begin{array}{l}\mathrm{LDL} \text { cholesterol (mg/dL) } \\
\text { (tertile) }\end{array}$} & $\leq 99$ (ref.) & 1.00 & - & - \\
\hline & $100-129$ & 1.18 & $0.70-1.98$ & 0.531 \\
\hline & $\geq 130$ & 0.83 & $0.49-1.41$ & 0.493 \\
\hline \multirow{3}{*}{$\begin{array}{l}\text { VLDL cholesterol (mg/dL) } \\
\text { (tertile) }\end{array}$} & $\leq 20$ (ref.) & 1.00 & - & - \\
\hline & $21-31$ & 0.59 & $0.35-1.01$ & $0.051 *$ \\
\hline & $\geq 32$ & 1.00 & $0.59-1.69$ & 1.000 \\
\hline \multirow{3}{*}{$\begin{array}{l}\text { Urea }(\mathrm{mg} / \mathrm{dL}) \\
\text { (tertile) }\end{array}$} & $\leq 30$ (ref.) & 1.00 & - & - \\
\hline & $31-39$ & 1.21 & $0.71-2.08$ & 0.480 \\
\hline & $\geq 40$ & 2.01 & $1.19-3.41$ & $0.010^{*}$ \\
\hline \multirow{3}{*}{$\begin{array}{l}\text { Creatinine (mg/dL) } \\
\text { (tertile) }\end{array}$} & $\leq 0.7$ (ref.) & 1.00 & - & - \\
\hline & $0.8-1.0$ & 0.85 & $0.48-1.50$ & 0.569 \\
\hline & $\geq 1.1$ & 1.96 & $1.05-3.66$ & $0.034^{*}$ \\
\hline \multirow{3}{*}{$\begin{array}{l}\text { DHEA }(\mathrm{ng} / \mathrm{mL}) \\
\text { (tertile) }\end{array}$} & $\leq 2.31$ (ref.) & 1.00 & - & - \\
\hline & $2.32-4.28$ & 0.90 & $0.54-1.52$ & 0.699 \\
\hline & $\geq 4.29$ & 0.98 & $0.58-1.63$ & 0.922 \\
\hline \multirow{3}{*}{$\begin{array}{l}\text { Hydroxyvitamin D ( } \mathrm{ng} / \mathrm{mL}) \\
\text { (tertile) }\end{array}$} & $\geq 25$ (ref.) & 1.00 & - & - \\
\hline & $19-24$ & 0.96 & $0.58-1.59$ & 0.880 \\
\hline & $\leq 18$ & 1.10 & $0.66-1.84$ & 0.720 \\
\hline \multirow{3}{*}{$\begin{array}{l}\text { Insulin }(\mu \mathrm{mol} / \mathrm{L}) \\
\text { (tertile) }\end{array}$} & $\geq 9$ (ref.) & 1.00 & - & - \\
\hline & $5-8$ & 1.31 & $0.79-2.16$ & 0.298 \\
\hline & $\leq 4$ & 0.93 & $0.55-1.55$ & 0.769 \\
\hline \multirow{3}{*}{$\begin{array}{l}\text { Triglycerides (mg/dL) } \\
\text { (em tertile) }\end{array}$} & $\leq 103$ (ref.) & 1.00 & - & - \\
\hline & 104-158 & 0.53 & $0.32-0.90$ & $0.019 *$ \\
\hline & $\geq 159$ & 0.88 & $0.53-1.47$ & 0.627 \\
\hline \multirow{3}{*}{$\begin{array}{l}\text { Total cholesterol (mg/dL) } \\
\text { (tertile) }\end{array}$} & $\leq 174$ (ref.) & 1.00 & - & - \\
\hline & $175-211$ & 1.16 & $0.69-1.94$ & 0.577 \\
\hline & $\geq 212$ & 0.72 & $0.43-1.21$ & 0.211 \\
\hline \multirow{3}{*}{$\begin{array}{l}\text { S-DHEA }(\mu \mathrm{g} / \mathrm{dL}) \\
\text { (tertile) }\end{array}$} & $\leq 36$ (ref.) & 1.00 & - & - \\
\hline & $37-73$ & 1.17 & $0.69-1.97$ & 0.556 \\
\hline & $\geq 74$ & 1.37 & $0.81-2.30$ & 0.243 \\
\hline \multirow{2}{*}{$\begin{array}{l}\text { IGF-1 (ng/mL) } \\
\text { (tertile) }\end{array}$} & $\leq 91.5$ (ref.) & 1.00 & - & - \\
\hline & $\begin{array}{l}91.6-134.3 \\
\geq 134.4\end{array}$ & $\begin{array}{l}0.98 \\
1.14\end{array}$ & $\begin{array}{l}0.58-1.64 \\
0.68-1.91\end{array}$ & $\begin{array}{l}0.932 \\
0.621\end{array}$ \\
\hline
\end{tabular}


Table 3 Results of the univariate ordinal logistic regression analysis among groups (frail vs pre-frail vs non-frail) (Continued)

\begin{tabular}{|c|c|c|c|c|}
\hline \multirow[b]{2}{*}{ Variable } & \multirow[b]{2}{*}{ Category } & \multicolumn{2}{|c|}{ Univariate Regression } & \multirow[b]{2}{*}{$p$-value } \\
\hline & & O.R. & $95 \% \mathrm{Cl}$ & \\
\hline \multirow{3}{*}{$\begin{array}{l}\text { Glycated hemoglobin (\%) } \\
\text { (tertile) }\end{array}$} & $\leq 5.5$ (ref.) & 1.00 & - & - \\
\hline & $5.6-6.3$ & 0.70 & $0.41-1.17$ & 0.173 \\
\hline & $\geq 6.4$ & 0.90 & $0.54-1.51$ & 0.694 \\
\hline \multirow{3}{*}{$\begin{array}{l}\text { IL-10 (pg/dL) } \\
\text { (tertile) }\end{array}$} & $\leq 0.39$ (ref.) & 1.00 & - & - \\
\hline & $0.40-1.05$ & 1.11 & $0.63-1.96$ & 0.720 \\
\hline & $\geq 1.06$ & 1.31 & $0.74-2.32$ & 0.362 \\
\hline \multirow{3}{*}{$\begin{array}{l}\text { IL-1a (pg/dL) } \\
\text { (tertile) }\end{array}$} & $\leq 0.60$ (ref.) & 1.00 & - & - \\
\hline & $0.70-3.35$ & 1.30 & $0.74-2.28$ & 0.355 \\
\hline & $\geq 3.36$ & 1.22 & $0.69-2.13$ & 0.498 \\
\hline \multirow{3}{*}{$\begin{array}{l}\mathrm{IL}-1 \beta \\
\text { (tertile) }\end{array}$} & $\leq 0.86$ (ref.) & 1.00 & - & - \\
\hline & $0.87-2.30$ & 1.21 & $0.69-2.12$ & 0.507 \\
\hline & $\geq 2.31$ & 1.47 & $0.83-2.59$ & $0.183^{*}$ \\
\hline \multirow{3}{*}{$\begin{array}{l}\mathrm{IL}-6 \\
\text { (tertile) }\end{array}$} & $\leq 1.50$ (ref.) & 1.00 & - & - \\
\hline & $1.51-2.60$ & 1.62 & $0.96-2.72$ & $0.071^{*}$ \\
\hline & $\geq 2.61$ & 1.67 & $0.99-2.81$ & $0.052^{*}$ \\
\hline \multirow{3}{*}{$\begin{array}{l}\text { TNF-a } \\
\text { (tertile) }\end{array}$} & $\leq 0.96$ (ref.) & 1.00 & - & - \\
\hline & $0.97-2.89$ & 0.92 & $0.53-1.61$ & 0.776 \\
\hline & $\geq 2.90$ & 0.99 & $0.57-1.76$ & 0.993 \\
\hline \multirow{3}{*}{$\begin{array}{l}\text { TNF- } \beta \\
\text { (tertile) }\end{array}$} & $\leq 0.29$ (ref.) & 1.00 & - & - \\
\hline & $0.30-0.80$ & 1.24 & $0.70-2.20$ & 0.459 \\
\hline & $\geq 0.81$ & 2.39 & $1.33-4.28$ & $0.003 *$ \\
\hline
\end{tabular}

Variables with $\mathrm{P}<0.20$ were entered in the multivariable logistic regression model, $n=347$. Notes: OR: Odds ratio shows the increase in odds for frailty. $95 \% \mathrm{Cl}=$ $95 \%$ of confidence interval for odds ratio; ref. = category chosen as reference. ${ }^{*}$ Values with statistical significance $(p<0.2)$

All other bold entries represent the $p$ values of significant results

process itself were suggested as mainly factors to drive this phenomenon that results in a low-grade chronic inflammatory state [49]. However, it is difficult to establish the relationship between inflammation and frailty, considering that both conditions linearly increase with advancing age, thus avoiding a clear answer to determine whether inflammation is a cause or a consequence of the frailty phenotype. Nevertheless, in a recent meta-analysis involving 32 cross-sectional studies and 23,910 older people, it was demonstrated that frail and pre-frail conditions are related to increased levels of serum cytokines, when compared to the levels of non-frail participants [50]. Our results corroborate the literature, demonstrating that an increased pro-inflammatory state is also present in frail older adults living in a context of social vulnerability.

Using an ordinal regression model, we found that TNF- $\beta$ was significantly associated to the frail phenotype. Abnormalities in TNF- $\alpha$ or TNF- $\beta$ expression have been implicated in several diseases [51-53]. A TNF- $\beta$ signaling pathway seems to be involved in the support of efficient immune responses against pathogens, which is a key point in the immunosenescense [54]. An important link between the lack of adaptability of immunological function during aging and increased risk for frailty in the vulnerable oldest old individuals was found in our study and may indicate that imbalances in immune functions seem to trigger physical frailty in this population. Similarly, in a systematic and meta-analysis review, Soysal and co-workers [50] demonstrated that three large prospective studies failed to find any association between higher inflammatory levels and frailty. The authors attribute this result to the paucity of data, to an over-adjustment of the analyses and/or to the fact that frail people were prone to diseases that might have increased the levels of inflammatory cytokines during the follow-up period and the lack of an adjustment for inherent changes to these markers in their analyses.

As an important limitation of this work, we can point out that this is a cross-sectional study, which does not follow individuals over time. A follow-up study using the same approaches to investigate frailty in this population is currently underway in our group. On the other hand, the statistical power of our sample size allows the expansion of our findings to other already recognized socially vulnerable populations. Notwithstanding, the knowledge of the characteristics related to socioeconomic and biological conditions configures an important tool to raise 
Table 4 Results of multivariable ordinal logistic regression for frailty $(n=257)$

\begin{tabular}{|c|c|c|c|c|}
\hline Variable & Category & O.R. & $95 \% \mathrm{Cl}$ & $p$-value \\
\hline \multirow[t]{2}{*}{ Sex } & Female (ref.) & 1.00 & - & - \\
\hline & Male & 1.61 & $0.89-2.92$ & 0.116 \\
\hline \multirow[t]{3}{*}{ Age } & 60-69 years (ref.) & 1.00 & - & - \\
\hline & $70-79$ years & 1.26 & $0.72-2.21$ & 0.422 \\
\hline & $\geq 80$ years & 2.47 & $1.09-5.61$ & $0.031 *$ \\
\hline \multirow{3}{*}{$\begin{array}{l}\mathrm{HDL} \\
\text { (mg/dL, tertile) }\end{array}$} & $\geq 51$ (ref.) & 1.00 & - & - \\
\hline & $42-50$ & 1.02 & $0.55-1.89$ & 0.942 \\
\hline & $\leq 41$ & 1.03 & $0.53-2.02$ & 0.931 \\
\hline \multirow{3}{*}{$\begin{array}{l}\text { VLDL } \\
\text { (mg/dL, tertile) }\end{array}$} & $\leq 20$ (ref.) & 1.00 & - & - \\
\hline & $21-31$ & 1.49 & $0.21-10.51$ & 0.687 \\
\hline & $\geq 32$ & 1.38 & $0.09-21.22$ & 0.818 \\
\hline \multirow{3}{*}{$\begin{array}{l}\text { Urea } \\
\text { (mg/dL, tertile) }\end{array}$} & $\leq 30$ (ref.) & 1.00 & - & - \\
\hline & $31-39$ & 1.28 & $0.66-2.46$ & 0.469 \\
\hline & $\geq 40$ & 1.73 & $0.86-3.45$ & 0.123 \\
\hline \multirow{3}{*}{$\begin{array}{l}\text { Creatinine } \\
\text { (mg/dL, tertile) }\end{array}$} & $\leq 0.7$ (ref.) & 1.00 & - & - \\
\hline & $0.8-1.0$ & 0.67 & $0.33-1.34$ & 0.256 \\
\hline & $\geq 1.1$ & 1.21 & $0.51-2.91$ & 0.668 \\
\hline \multirow{3}{*}{$\begin{array}{l}\text { Triglycerides } \\
\text { (mg/dL, tertile) }\end{array}$} & $\leq 103$ (ref.) & 1.00 & - & - \\
\hline & $104-158$ & 0.39 & $0.06-2.78$ & 0.350 \\
\hline & $\geq 159$ & 0.72 & $0.05-10.92$ & 0.810 \\
\hline \multirow{3}{*}{$\begin{array}{l}\text { IL-1 } 1 \beta \\
\text { (pg/mL, tertile) }\end{array}$} & $\leq 0.86$ (ref.) & 1.00 & - & - \\
\hline & $0.87-2.30$ & 1.05 & $0.54-2.05$ & 0.890 \\
\hline & $\geq 2.31$ & 0.88 & $0.44-1.74$ & 0.707 \\
\hline \multirow{3}{*}{$\begin{array}{l}\text { IL-6 } \\
\text { (pg/mL, tertile) }\end{array}$} & $\leq 1.50$ (ref.) & 1.00 & - & - \\
\hline & $1.51-2.60$ & 1.80 & $0.92-3.54$ & 0.088 \\
\hline & $\geq 2.61$ & 1.84 & $0.93-3.64$ & 0.078 \\
\hline \multirow{3}{*}{$\begin{array}{l}\text { TNF- } \beta \\
\text { (pg/mL, tertile) }\end{array}$} & $\leq 0.29$ (ref.) & 1.00 & - & - \\
\hline & $0.30-0.80$ & 1.14 & $0.59-2.18$ & 0.698 \\
\hline & $\geq 0.81$ & 2.53 & $1.30-4.90$ & $0.006^{*}$ \\
\hline
\end{tabular}

Notes: OR (Odds Ratio) $=$ risk of frailty. $95 \% \mathrm{Cl}=95 \%$ Confidence interval for odds ratio. *Values with statistical significance $(p<0.05)$

Score Test for the Proportional Odds Assumption: $X 2=17.59 ; D F=19 ; P=$

$0.550 ; n=29$ non-frail, $n=143$ pre-frail and $n=85$ frail

All other bold entries represent the $p$ values of significant results

preventive strategies to decrease frailty risk in the most vulnerable populations.

\section{Conclusions}

Taken together, the results presented here could help to implement preventive healthcare strategies by evaluating frailty and at the same time measuring a set of inflammatory biomarkers, paying special attention to TNF- $\beta$ plasmatic levels. This could enable health teams to plan and improve care actions for this population, especially in the community and in primary health services.

\section{Additional file}

Additional file 1: Description of the Paulista Social Vulnerability Index. (DOCX $19 \mathrm{~kb})$

\section{Abbreviations}

BMI: Body Mass Index; DHEA: Dehydroepiandrosterone; DHEA-

S: Dehydroepiandrosterone sulfate; GDS: Geriatric Depression Scale;

GH: Human Growth Hormone; IGF-1: Insulin-like Growth Factor-1; IL-

1a: Interleukin-1 a; IL-13: Interleukin-1 B; IL-6: Interleukin-6; IPAQ: International Physical Activity Questionnaire; SVI: Social Vulnerability Index; TNFa: Tumor Necrosis Factor a; TNF $\beta$ : Tumor Necrosis Factor $\beta$

\section{Acknowledgments}

The authors are grateful to the team of gerontologists and nurses who performed the data collection and biological material and to all the family members and older adults who participated in this study.

\section{Funding}

This work was supported by the Research Program for SUS-PPSUS/Ministry of Health and São Paulo Research Foundation (FAPESP) grant \#2014/50104-0, the National Council for Scientific and Technological Development (CNPq) and the Coordination of Improvement of Higher Education Personnel - Brazil (CAPES) Grant \#001. CMCN has a postdoc fellowship from FAPESP, grant \#2014/21066-2.

\section{Availability of data and materials}

The datasets used and/or analyzed during the current study are available from the corresponding author on reasonable request.

\section{Authors' contributions}

CMCN collected and analyzed the data; GAOG, FSO, KG-S, FAV, ACMG, MSZ, SCIP, MRC participated in the conception and design of the study; CMCN and MRC prepared the manuscript. All authors revised the final version of the manuscript. The sponsors of this study were not involved in the design, methods, subject recruitment, data collections, analysis, or preparation of paper. All authors read and approved the final manuscript.

\section{Ethics approval and consent to participate}

An informed consent form received ethics approval from the Federal University of São Carlos Ethics Committee on Human Experimentation (860,653/2014). Written informed consent for the conduct of the survey was obtained from each participant, and complete anonymity of participants was ensured.

\section{Competing interests}

The authors declare that they have no competing interests.

\section{Publisher's Note}

Springer Nature remains neutral with regard to jurisdictional claims in published maps and institutional affiliations.

Received: 27 April 2018 Accepted: 23 October 2018

Published online: 06 November 2018

\section{References}

1. Fried LP, Tangen CM, Walston J, Newman AB, Hirsch C, Gottdiener J, Seeman T, Tracy R, Kop WJ, Burke G, et al. Frailty in older adults: evidence for a phenotype. J Gerontol A Biol Sci Med Sci. 2001;56(3):M146-56.

2. Kulmala J, Nykanen I, Hartikainen S. Frailty as a predictor of all-cause mortality in older men and women. Geriatr Gerontol Int. 2014;14(4):899-905.

3. Mitnitski AB, Rutenberg AD, Farrell S, Rockwood K. Aging, frailty and complex networks. Biogerontology. 2017;18(4):433-46.

4. Andrew MK, Keefe JM. Social vulnerability from a social ecology perspective: a cohort study of older adults from the National Population Health Survey of Canada. BMC Geriatr. 2014;14:90.

5. Andrew MK, Mitnitski AB, Rockwood K. Social vulnerability, frailty and mortality in elderly people. PLoS One. 2008;3(5):e2232.

6. Andrew MK. Frailty and social vulnerability. Interdiscip Top Gerontol Geriatr. 2015;41:186-95 
7. Andrew MK, Rockwood K. Social vulnerability predicts cognitive decline in a prospective cohort of older Canadians. Alzheimers Dement. 2010;6(4):319-25 e311.

8. Curcio CL, Henao GM, Gomez F. Frailty among rural elderly adults. BMC Geriatr. 2014;14:2.

9. De Martinis M, Franceschi C, Monti D, Ginaldi L. Inflammation markers predicting frailty and mortality in the elderly. Exp Mol Pathol. 2006:80(3):219-27.

10. Franceschi C, Bonafe M, Valensin S, Olivieri F, De Luca M, Ottaviani E, De Benedictis G. Inflamm-aging. An evolutionary perspective on immunosenescence. Ann N Y Acad Sci. 2000;908:244-54.

11. Chang SS, Weiss CO, Xue QL, Fried LP. Association between inflammatoryrelated disease burden and frailty: results from the Women's health and aging studies (WHAS) I and II. Arch Gerontol Geriatr. 2012;54(1):9-15.

12. Mocchegiani $E$, Corsonello A, Lattanzio F. Frailty, ageing and inflammation: reality and perspectives. Biogerontology. 2010;11(5):523-5.

13. Baylis D, Bartlett DB, Syddall HE, Ntani G, Gale CR, Cooper C, Lord JM, Sayer AA. Immune-endocrine biomarkers as predictors of frailty and mortality: a 10-year longitudinal study in community-dwelling older people. Age. 2013; 35(3):963-71.

14. Hubbard RE, Woodhouse KW. Frailty, inflammation and the elderly. Biogerontology. 2010;11(5):635-41.

15. Darvin K, Randolph A, Ovalles S, Halade D, Breeding L, Richardson A, Espinoza SE. Plasma protein biomarkers of the geriatric syndrome of frailty. J Gerontol A Biol Sci Med Sci. 2014;69(2):182-6.

16. Kanapuru B, Ershler WB. Inflammation, coagulation, and the pathway to frailty. Am J Med. 2009;122(7):605-13.

17. Puts MTE, Visser M, Twisk JWR, Deeg DJH, Lips P. Endocrine and inflammatory markers as predictors of frailty. Clin Endocrinol. 2005;63(4):403-11.

18. Calvani R, Marini F, Cesari M, Tosato M, Anker SD, von Haehling S, Miller RR, Bernabei R, Landi F, Marzetti E, et al. Biomarkers for physical frailty and sarcopenia: state of the science and future developments. J Cachexia Sarcopenia Muscle. 2015;6(4):278-86.

19. Cesari M, Penninx BW, Pahor M, Lauretani F, Corsi AM, Rhys Williams G, Guralnik $J M$, Ferrucci L. Inflammatory markers and physical performance in older persons: the InCHIANTI study. J Gerontol A Biol Sci Med Sci. 2004:59(3):242-8.

20. Tiainen $K$, Hurme M, Hervonen A, Luukkaala T, Jylha M. Inflammatory markers and physical performance among nonagenarians. A Biol Sci Med Sci. 2010;65(6):658-63.

21. Visser $M$, Pahor $M$, Taaffe $D R$, Goodpaster BH, Simonsick EM, Newman AB, Nevitt M, Harris TB. Relationship of interleukin-6 and tumor necrosis factoralpha with muscle mass and muscle strength in elderly men and women: the health ABC study. J Gerontol A Biol Sci Med Sci. 2002;57(5):M326-32.

22. Verghese J, Holtzer R, Oh-Park M, Derby CA, Lipton RB, Wang C. Inflammatory markers and gait speed decline in older adults. J Gerontol A Biol Sci Med Sci. 2011;66(10):1083-9.

23. Penninx BW, Kritchevsky SB, Newman AB, Nicklas BJ, Simonsick EM, Rubin S, Nevitt M, Visser M, Harris T, Pahor M. Inflammatory markers and incident mobility limitation in the elderly. J Am Geriatr Soc. 2004;52(7):1105-13.

24. Penninx BWJH, Pahor M, Cesari M, Corsi AM, Woodman RC, Bandinelli S, Guralnik JM, Ferrucci L. Anemia is associated with disability and decreased physical performance and muscle strength in the elderly. J Am Geriatr Soc 2004:52(5):719-24.

25. Visser M, Kritchevsky SB, Newman AB, Goodpaster BH, Tylavsky FA, Nevitt MC, Harris TB, Composition HAB. Lower serum albumin concentration and change in muscle mass: the health, Aging and Body Composition Study. Am J Clin Nutr. 2005:82(3):531-7.

26. Voznesensky M, Walsh S, Dauser D, Brindisi J, Kenny AM. The association between dehydroepiandosterone and frailty in older men and women. Age Ageing. 2009;38(4):401-6

27. Araujo AB, Travison TG, Bhasin S, Esche GR, Williams RE, Clark RV, McKinlay JB: Association between testosterone and estradiol and age-related decline in physical function in a diverse sample of men. J Am Geriatr Soc 2008, 56(11):2000-2008

28. Onder G, Liperoti R, Russo A, Soldato M, Capoluongo E, Volpato S, Cesari M, Ameglio F, Bernabei R, Landi F. Body mass index, free insulin-like growth factor I, and physical function among older adults: results from the ilSIRENTE study. Am J Phys Endocrinol Metab. 2006;291(4):E829-34.

29. Mastaglia SR, Seijo M, Muzio D, Somoza J, Nunez M, Oliveri B. Effect of vitamin D nutritional status on muscle function and strength in healthy women aged over sixty-five years. J Nutr Health Aging. 2011;15(5):349-54.

30. Zazzetta MS, Gomes GA, Orlandi FS, Gratao AC, Vasilceac FA, Gramani-Say K Ponti MA, Castro PC, Pavarini SC, Menezes AL, et al. Identifying frailty levels and associated factors in a population living in the context of poverty and social vulnerability. J Frailty Aging. 2017;6(1):29-32.

31. Pessoa VM, Rigotto RM, Carneiro FF, Teixeira AC. Meanings and methods of territorialization in primary health care. Cien Saude Colet. 2013;18(8):2253-62

32. Dados S-FSEdAd. Índice Paulista de Vulnerabilidade Social, vol. 17. São Paulo: Fundação SEADE; 2013.

33. Nunes DP, Duarte YA, Santos JL, Lebrao ML. Screening for frailty in older adults using a self-reported instrument. Revista de saude publica. 2015;49:2.

34. Batistoni SST, Neri AL, Cupertino APFB. Validity of the center for epidemiological studies depression scale among brazilian elderly. Revista de saude publica. 2007;41(4):598-605.

35. Hagstromer M, Oja P, Sjostrom M. The international physical activity questionnaire (IPAQ): a study of concurrent and construct validity. Public Health Nutr. 2006;9(6):755-62.

36. Brucki SM, Nitrini R, Caramelli P, Bertolucci PH, Okamoto IH. Suggestions for utilization of the mini-mental state examination in Brazil. Arq Neuropsiquiatr. 2003;61(3B):777-81.

37. Almeida OP, Almeida SA. Reliability of the Brazilian version of the + +abbreviated form of geriatric depression scale (GDS) short form. Arq Neuropsiquiatr. 1999;57(2B):421-6.

38. Pereira AA, Borim FSA, Neri AL. Absence of association between frailty index and survival in elderly Brazilians: the FIBRA study. Cad Saude Publica. 2017; 33(5):e00194115.

39. Collard RM, Boter H, Schoevers RA, Oude Voshaar RC. Prevalence of frailty in community-dwelling older persons: a systematic review. J Am Geriatr Soc. 2012;60(8):1487-92.

40. Moreira VG, Lourenco RA. Prevalence and factors associated with frailty in an older population from the city of Rio de Janeiro, Brazil: the FIBRA-RJ study. Clinics. 2013;68(7):979-85.

41. Sousa AC, Dias RC, Maciel AC, Guerra RO. Frailty syndrome and associated factors in community-dwelling elderly in Northeast Brazil. Arch Gerontol Geriatr. 2012:54(2):e95-e101.

42. Buckinx F, Rolland Y, Reginster JY, Ricour C, Petermans J, Bruyere O. Burden of frailty in the elderly population: perspectives for a public health challenge. Arch Public Health. 2015;73(1):19.

43. Gordon EH, Peel NM, Samanta M, Theou O, Howlett SE, Hubbard RE. Sex differences in frailty: a systematic review and meta-analysis. Exp Gerontol. 2017:89:30-40.

44. Theou O, Rockwood MR, Mitnitski A, Rockwood K. Disability and comorbidity in relation to frailty: how much do they overlap? Arch Gerontol Geriatr. 2012:55(2):e1-8.

45. Banks J, Muriel A, Smith JP. Disease prevalence, disease incidence, and mortality in the United States and in England. Demography. 2010; 47(Suppl):S211-31.

46. de Azevedo Barros MB, Lima MG, LdPB M, Szwarcwald CL, Malta DC. Social inequalities in health behaviors among Brazilian adults: National Health Survey, 2013. Int J Equity Health. 2016;15(1):148.

47. Boccolini CS, de Souza Junior PR. Inequities in healthcare utilization: results of the Brazilian National Health Survey, 2013. Int J Equity Health. 2016;15(1):150

48. Goronzy JJ, Weyand CM. Understanding immunosenescence to improve responses to vaccines. Nat Immunol. 2013;14(5):428-36.

49. Wilson D, Jackson T, Sapey E, Lord JM. Frailty and sarcopenia: the potential role of an aged immune system. Ageing Res Rev. 2017:36:1-10.

50. Soysal P, Stubbs B, Lucato P, Luchini C, Solmi M, Peluso R, Sergi G, Isik AT, Manzato E, Maggi S, et al. Inflammation and frailty in the elderly: a systematic review and meta-analysis. Ageing Res Rev. 2016;31:1-8.

51. Komaki Y, Yamada A, Komaki F, Kudaravalli P, Micic D, Ido A, Sakuraba A. Efficacy, safety and pharmacokinetics of biosimilars of anti-tumor necrosis factor-alpha agents in rheumatic diseases; a systematic review and metaanalysis. J Autoimmun. 2017;79:4-16.

52. Willrich MA, Murray DL, Snyder MR. Tumor necrosis factor inhibitors: clinical utility in autoimmune diseases. Transl Res. 2015;165(2):270-82.

53. Speeckaert MM, Speeckaert R, Laute M, Vanholder R, Delanghe JR. Tumor necrosis factor receptors: biology and therapeutic potential in kidney diseases. Am J Nephrol. 2012;36(3):261-70.

54. Tumanov AV, Christiansen PA, Fu YX. The role of lymphotoxin receptor signaling in diseases. Curr Mol Med. 2007;7(6):567-78. 